\title{
THE EFFECT OF THE DYNAMIC WHEEL LOAD AND MEASUREI SOIL BEHAVIOR ON STABILITY OF TRACKED VEHICLES
}

ka AbdElGawwad, A. M. A. A AbouEINour

\begin{abstract}
The randomly input from the surface and consequently the wheels dynamic loads has a significant influence on the tracked vehicle ride and its stability. However, the tracked vehicle always travels over a deformable terrain with major obstacles. So it is important to conjunct between the ride responses and the stability models of the tracked vehicle moving on the soft soil. In this paper, a vertical dynamic tracked vehicle six degrees of freedom and the forces at the track-terrain interaction models were provided. The soil parameters have three types of soil; sand, clay and wet ciay are measured. These measured parameters are used in the developed mathematical model to study the effect of the roadwheel dynamic load on the normal force, rolling resistance force, tractive force and drawbar pull at each of roadwheel. The present paper introduced new figures of the interaction forces time history between track and terrain. Also, the effect of different types of soil on the tracked vehicle stability was presented. The results showed that, the measured soil parameters were helpful for the model to provide accurate results. The terrain surface parameters have a significant influence on the tracked vehicle ride parameters. The time history of the interaction forces between track and terrain surface is helpful to understand the phenomenon of terramechanics. The clay soil provides higher tractive force and drawbar pull than the sand soil
\end{abstract}

